\title{
Real Estate in the Mixed-asset Portfolio: The Question of Consistency
}

\author{
Stephen Lee ${ }^{\dagger}$ and Simon Stevenson‡ \\ †Centre for Real Estate Research (CRER) \\ The University of Reading Business School, \\ Reading, RG6 6AW \\ England
}

\author{
Phone: +44 118931 6338, Fax: +44 118931 8172, E-mail: S.L.Lee@reading.ac.uk \\ \$ Department of Banking \& Finance, Graduate School of Business, \\ University College Dublin, Blackrock, Co Dublin, Ireland.
}

Phone: +353 1706 8825, Fax: +353 1283 5482, E-mail: simon.stevenson@ucd.ie

\begin{abstract}
The recent poor performance of the equity market in the UK has meant that real estate is increasingly been seen as an attractive addition to the mixed-asset portfolio. However, determining whether the good return enjoyed by real estate is a temporary or long-term phenomenon is a question that remains largely unanswered. In other words, there is little or no evidence to indicate whether real estate should play a consistent role in the mixed-asset portfolio over short- and long-term investment horizons. Consistency in this context refers to the ability of an asset to maintain a positive allocation in an efficient portfolio over different holding periods. Such consistency is a desirable trait for any investment, but takes on particular significance when real estate is considered, as the asset class is generally perceived to be a longterm investment due to illiquidity. From an institutional investor's perspective, it is therefore crucial to determine whether real estate can be reasonably expected to maintain a consistent allocation in the mixed-asset portfolio in both the short and long run and at what percentage. To address the question of consistency the allocation of real estate in the mixed-asset portfolio was calculated over different holding periods varying from 5- to 25-years.
\end{abstract}

Keywords: Mixed-asset portfolios, Consistency, Marginal impact 


\section{Real Estate in the Mixed-asset Portfolio: The Question of Portfolio Consistency}

\section{Introduction}

The recent poor performance of the equity market in the UK has meant that real estate is increasingly been seen as an attractive addition to the mixed-asset portfolio. However, investors might question whether the performance of real estate will remain competitive with other assets over varying time periods. For instance, the relatively good returns of real estate in the UK during the 1970s, mainly as a result of the high levels of inflation, were lost in the 1980s. Thus, determining whether the good return enjoyed by real estate is a temporary or long-term phenomenon is a question that remains largely unanswered. In other words, there is little or no evidence to indicate whether real estate would play a consistent role in the mixed-asset portfolio over short- and long-term investment horizons ${ }^{1}$. Consistency in this context refers to the ability of an asset to maintain a positive allocation in an efficient portfolio over different holding periods. Such consistency is a desirable trait for any investment, but takes on particular significance when real estate is considered, as the asset class is generally perceived to be a long-term investment due to illiquidity. From an institutional investor's perspective, it is therefore crucial to determine whether real estate can be reasonably expected to maintain a consistent allocation in the mixedasset portfolio in both the short and long run and at what percentage.

To address the question of consistency the allocation of real estate in the mixed-asset portfolio was calculated over different holding periods varying from 5- to 25-years. The incremental impact of including real estate was then examined by comparing the risk of efficient portfolios with and without real estate for the same level of return and the return of portfolios with and without property at the same level of risk. The general conclusions of which are that real estate does fairly consistently provide both return enhancement and risk reduction benefits. While, this does vary to some extent over time, it is broadly consistent over the various investment horizons analysed. The results also illustrate that real estate provides the greatest benefits in the low risk and return optimal portfolios, with the results less obvious at the high risk/return end of the efficient frontier. Finally, the benefit from holding real estate appears to shift as an investor moves along the efficient frontier. At the upper return end of the frontier it would appear that greater benefits are due to the return enhancement qualities of real estate, however, at the lower end of the frontier, the assets risk reduction qualities tend to dominate.

The paper is set out as follows. The next section outlines the research design. The following discusses the data used. Section 4 reports the empirical findings, while Section 5 contains concluding remarks.

\footnotetext{
${ }^{1}$ See Sivitanides (1997) for the only other example of an analysis similar to the present study using US data from 1978-1995.
} 


\section{Research Design}

\section{Efficient Frontiers}

To investigate the issue of whether real estate allocations in efficient portfolios are consistent over varying time horizons, efficient frontiers were calculated by minimising portfolio risk for different levels of portfolio return, where risk is defined as the variance of returns, or more typically the standard deviation of returns. In other words, a portfolio is on the efficient frontier if it has:

- The highest expected return for a given level of risk, or

- The lowest level of risk for a given expected return

Mathematically, portfolios along the efficient frontier are determined by solving the following parametric quadratic programming problem (Markowitz, 1952):

$$
\begin{gathered}
\text { Minimise } \sigma_{\text {Port }}^{2}=\sum_{\mathrm{i}=1}^{\mathrm{N}} \mathrm{w}_{\mathrm{i}}^{2} \sigma_{\mathrm{i}}^{2}+2 \sum_{\mathrm{i}=1}^{\mathrm{N}} \sum_{\substack{\mathrm{j}=1 \\
\mathrm{j}>\mathrm{i}}}^{\mathrm{N}} \mathrm{w}_{\mathrm{i}} \mathrm{w}_{\mathrm{j}} \sigma_{\mathrm{ij}} \\
\mathrm{E}\left(\mathrm{R}_{\text {Port }}\right)=\sum_{\mathrm{i}=1}^{\mathrm{N}} \mathrm{w}_{\mathrm{i}} \mathrm{E}\left(\mathrm{R}_{\mathrm{i}}\right) \\
0 \leq \mathrm{w}_{\mathrm{i}} \leq 1 \\
\sum_{\mathrm{i}=1}^{\mathrm{N}} \mathrm{w}_{\mathrm{i}}=1
\end{gathered}
$$

where:

$$
\begin{array}{ll}
\mathrm{w}_{\mathrm{i}} & =\text { the weight associated with asset class } \mathrm{i} \\
\sigma_{\mathrm{i}}^{2} & =\text { the variance of asset } \mathrm{i} \\
\sigma_{\mathrm{ij}} & =\text { the covariance between asset classes } \mathrm{i} \text { and } \mathrm{j} \\
\mathrm{N} & =\text { the number of asset classes. } \\
\mathrm{E}\left(\mathrm{R}_{\mathrm{i}}\right) & =\text { the expected return of asset class } \mathrm{i} \\
\mathrm{E}\left(\mathrm{R}_{\text {Port }}\right) & =\text { the expected return of the portfolio }
\end{array}
$$

The efficient frontier then is the locus of points joining these efficient portfolios, where the weights of the portfolio must be positive (no short sales allowed) and the fractions (asset proportions) of the total portfolio must sum to one. Since the expected return for each asset is fixed, as is its standard deviation and covariance (correlation) with other assets, the efficient portfolio is found by varying the proportion of funds allocated to each asset class.

However, the simple application of the above equations to calculate efficient portfolios leads to some assets in the efficient portfolios taking zero weights while others have very large allocations. Black and Litterman (1992) refer to these as corner solutions and although the resulting portfolios are optimal in the statistical sense, the results would be unacceptable to any prudent portfolio manager (Jorion, 1985). These unrealistic portfolio combinations stem from two well-recognised problems in the literature. 
First, the returns of direct real estate are appraisal rather than market based and there is a strong view that as a consequence the volatility of real estate has been considerably underestimated (see Fisher et al, 1994 and Corgel and deRoos, 1999). However, while views are divided as to whether appraisal-smoothing bias exists and whether it can be appropriately corrected, it seems that the issue is of more concern when comparing real estate with market based securities, such as equities and bonds. Otherwise, when optimisers consider real estate as part of the mixed-asset portfolio, the highly attractive features of the appraisal-based returns have made real estate a significant percentage of the efficient portfolio, far in excess of that observed in reality. For instance, allocations to direct real estate in excess of 50 percent have been implied in a number of studies (Seiler et al, 1999). Thus, any examination of real estate in the mixed-asset portfolio therefore needs to be assessed with a more acceptable time-series of real estate returns. This is achieved by de-smoothing the appraisal-based data.

Second, Michaud (1989) argues that optimisers are essentially "estimation-error maximisers" in that risk and return inputs are invariably subject to estimation error, even using historic data. As a result optimisers significantly overweight those assets with large estimated returns, negative or low positive correlation and small variances. Michaud (1989) contending that assets that display these features, such as appraisalbased real estate data when it is compared with equities and bonds, are more than likely to have the largest estimation errors. This means that the expected return of the efficient portfolio is overstated, whilst its risk is understated. In addition, this problem is exacerbated as the number of assets increases with the errors accumulating rather than cancelling. Furthermore, the mean-variance model used above does not allow for short sales, which significantly increase the adverse effect of estimation error on the portfolio selection process (Jorion, 1992). Accordingly the successful examination of real estate in the mixed-asset portfolio requires a procedure that keeps estimation risk in check even if the real estate data used is more acceptable.

\section{De-smoothing and Constraints}

As noted above using direct real estate data raises the issue of how to deal with the socalled "smoothing bias" observed in appraisal based property indices. To account for such smoothing bias and to make the appraisal-based real estate data more comparably with the market based securities the real estate data was de-smoothed. The approach adopted here is to use the model suggested by Geltner (1993). However, it should be noted that no de-smoothing process is perfect and the choice of method may bias the results.

The second problem of estimation risk is ameliorated by placing restrictions (upper and lower bounds) on the amount which any one asset, or group of assets, can have in the optimum portfolios as it 'constrains' the impact of instability in the input parameters, Frost and Savarino (1988) and Chopra (1993), Chopra and Ziemba (1993) and Stevenson (2000).

The assets included in the analysis and their upper and lower bounds were as follows: 
- Equities (FTA Index): 40 to 60 percent;

- Bonds (5-15 year Gilts Index): 30 to 50 percent;

- Cash (Treasury Bills): 0 to 5 percent;

- Commercial Real Estate (JLL Index): 0 to 20 percent;

Equities were constrained to lie between 40 and 60 percent of the total; bonds were constrained to be between 30 to 50 percent of the total, and cash limited to no more than 5 percent. These upper and lower bounds represent the typical allocations to these asset classes by the average institutional investor in the UK over the last 30 years. In contrast, the maximum allocation of 20 percent in real estate is not intended to reflect the portfolio policy of any known institutional investor. Rather, the intent of this study is to explore how real estate affects overall portfolio risk and return, consequently, the constraint on real estate was therefore kept rather loose. Moreover, an allocation of 20 percent to real estate in the mixed-asset portfolio has been suggested as a viable level for this asset (Sweeney, 1988 and Fogler, 1984). This study, therefore, can examine whether a 20 percent allocation is attainable and consistent over various holding periods.

\section{Rolling Estimation}

Efficient frontiers were generated for 5- to 25-year rolling time periods, beginning in 1977Q4, and ending in 2002Q3. The 5-year rolling periods are defined as the quarterly returns from 1977Q4 through 1982Q3, 1978Q4 to 1983Q3, 1979Q4 to 1984Q3,.., 1998Q4 to 2002Q3. Ten-year rolling periods are 1977Q4 to 1986Q3, 1978Q4 to 1987Q3,.., 1993Q4 to 2002Q3. The 15- to 25-year rolling periods were defined similarly. There were therefore 21, 5-year rolling periods, 16, 10-year rolling periods, 11, 15-year rolling periods, 6 20-year rolling periods and 1 25-year observation making a total of 55 holding periods.

The choice of different holding periods was done to examine the impact of real estate in the mixed-asset portfolio over short- and long-term investment horizons. The 5year horizons representing the short term while the 10- and 15-year horizons are taken to represent the typical holding periods recommended and followed for direct real estate investment. For instance, Fisher and Young (2000) suggest that real estate analysts, owners, brokers, and appraisers in the US "habitually think of commercial property as having a tenure of 10 years”. While, Collett et al (2003) find that an average holding period of 13 years for properties held in the Investment Property Databank (IPD) over the period 1984 to 1996. The 20- and 25-year holding periods, therefore, represent the long-run investment horizon and can therefore be considered the strategic asset allocation of real estate in the mixed-asset portfolio.

For each rolling period, two efficient frontiers were calculated. In the first, real estate was permitted to enter the optimal solution in the second it was not. The objectives of such an approach are three-fold. First, to determine whether real estate consistently formed part of mixed-asset portfolios on the efficient frontier and what percentage of the total portfolio was allocated to real estate when it did so. Secondly, to see whether real estate increased portfolio returns over portfolios that contained no real estate, and the degree of return enhancement at each level of risk. Finally to see whether real estate reduced portfolio risk over portfolios that contained no real estate, 
and the degree of risk reduction at each level of return.

The efficient frontiers were each made up of 10 portfolios, where each portfolio represents a specific asset allocation, expected return, and standard deviation. The highest returns and standard deviations were associated with portfolio 1, the maximum return portfolio (MRP). Portfolios 2 through 9 had the next lowest returns and risks, while portfolio 10 represents the lowest risk and return portfolio, the minimum variance portfolio (MVP). Hence, a total of 1650 efficient portfolios were therefore calculated (550 for each of the 3 situations).

Returns, standard deviations, and real estate allocations for each portfolio were then averaged within each holding period. That is for the 5-year holding periods, a total of 21 observations were available for each portfolio. Fewer observations were available for successively longer periods, with 16 observations for the 10-year holding periods; 11 observations for the 15-year investment horizon; 6 for the 20-year investment horizon and only 1 for the 25-year holding period.

For each portfolio and holding period, the percentage of portfolios with real estate was computed, as was the average real estate allocation in the optimum solution. Finally, the risk and return differences between the two efficient frontiers, with and without real estate, were calculated to estimate real estate's marginal impact on portfolio performance. Calculating the return difference between the two efficient portfolios was done by subtracting the return of the portfolios on the efficient frontier with real estate from the return of the efficient frontier without real estate at the same level of risk (standard deviation). While the risk differences between efficient portfolios with real estate were compared with efficient portfolios without real estate at the same level of return².

\section{Data}

The data used in this study are the quarterly returns of equities, government bonds, cash and direct real estate. The returns of equities are represented by the FTA index, government bonds represented by 5-15 year Gilt index, cash is represented by the returns on T-bills and direct real estate is measured by the JLL Index, over the period 1977:Q4 to 2002:Q3 ${ }^{3}$ a total of 100 observations.

Means and standard deviations (SD) are calculated to provide a relative comparison of the different asset classes on both a risk and return basis. Correlation coefficients are then calculated to describe the co-movement between each asset class. The asset with the lowest correlation would usually be a good candidate for risk reduction in a portfolio through increased diversification. The summary statistics are shown in

\footnotetext{
${ }^{2}$ The analysis by Sivitanides (1997) is the closet in approach to the present study as it examines the allocation to real estate in the US mixed-asset portfolio for holding periods of 5, 10 and 18 years. However, the author does not de-smooth the real estate data and allows the allocations to the three asset classes to be unconstrained; consequently the allocations to real estate are extreme, i.e. over $70 \%$ in some cases. In addition Sivitanides (1997) only considers the efficient frontiers containing real estate and does not compare the impact on risk and return for the efficient frontiers with and without real estate.

${ }^{3}$ The reason for only considering the data from 1977Q4 is that the first return observation (1977Q3) is lost in the de-smoothing process used below.
} 
Table 1.

Table 1: Summary Statistics: Quarterly Data 1977:4: to 2002:3

\begin{tabular}{l|cccc}
\hline Panel A Statistics & JLL & FTA & Gilts & Cash \\
\hline Mean & 2.89 & 3.60 & 3.00 & 2.16 \\
SD & 4.37 & 8.73 & 5.62 & 0.79 \\
\hline Panel B Correlation & JLL & FTA & Gilts & Cash \\
\hline JLL & 1.000 & & & \\
FTA & 0.052 & 1.000 & & \\
Gilts & -0.075 & 0.442 & 1.000 & \\
Cash & -0.100 & 0.129 & 0.010 & 1.000 \\
\hline
\end{tabular}

The average quarterly return and SD for each of the three assets and direct real estate are presented in Panel A of Table 1. As observed in Panel A of Table 1 equities offered the highest returns compensating investors for the highest risk. Direct real estate, as represented by the JLL index, showing a lower risk than bonds even after de-smoothing. Panel B of Table 1 shows the correlation coefficients between the asset classes. The correlation between the three assets and direct real estate are all about zero and significantly lower than that between equities and bonds (0.44). Consequently, adding direct real estate to these assets should significantly reduce portfolio risk, even after de-smoothing the returns series to account for any appraisal bias.

\section{Results}

The empirical results examine the return enhancement and risk reduction benefits of incorporating direct real estate into a mixed-asset framework. As stated in the previous section, initially over the five different horizons, 10 efficient portfolios are estimated with the constraints specified, excluding real estate. Real estate is then allowed to enter the portfolios, firstly holding the initially estimated portfolio risk constant, and then the portfolio return. The results reported examine both the estimated allocation of real estate and the level by which firstly the portfolio return is enhanced and secondly how much the portfolio risk is reduced.

\section{Consistency}

Tables 2 and 3 presents the percentage of the time when real estate achieved a positive allocation in the mixed-asset portfolio and the percentage of the time real estate reached its upper bound, for the five different investment horizons, for the two tests (return enhancement, risk reduction) and for 10 portfolios on the efficient frontier. Table 2 shows that real estate was a component of optimised portfolios in almost ever period and in most portfolios on the efficient frontier. For instance, at the lower end of the risk/return frontier real estate tended to enter the mixed-asset portfolio almost 100 percent of the time, especially with the longer investment horizons. However, the number of times with a positive allocation to real estate declines as we move up the efficient frontier, with real estate only enters the MRP on a few occasions for the 5-year investment horizon. As Table 3 shows these results are almost identical when real estate is tested for risk reduction. 
Table 2: Percentage of the Time When Real Estate Achieved a Positive Allocation and Reached its Upper Bound (Enhancing Returns)

\begin{tabular}{|c|c|c|c|c|c|c|c|c|c|c|}
\hline & \multicolumn{5}{|c|}{$\begin{array}{l}\text { Percentage of the Time When Real } \\
\text { Estate Achieved a Positive Allocation }\end{array}$} & \multicolumn{5}{|c|}{$\begin{array}{l}\text { Percentage of the Time when Real } \\
\text { Estate Reached its Upper Bound }\end{array}$} \\
\hline & 5 & 10 & 15 & 20 & 25 & 5 & 10 & 15 & 20 & 25 \\
\hline 1 MRP & 14 & $\mathbf{0}$ & $\mathbf{0}$ & 0 & $\mathbf{0}$ & 5 & $\mathbf{0}$ & $\mathbf{0}$ & $\mathbf{0}$ & $\mathbf{0}$ \\
\hline 2 & 52 & 63 & 55 & 67 & 100 & 5 & $\mathbf{0}$ & $\mathbf{0}$ & $\mathbf{0}$ & 0 \\
\hline 3 & 52 & 69 & 64 & 50 & 100 & 5 & $\mathbf{0}$ & $\mathbf{0}$ & $\mathbf{0}$ & 0 \\
\hline 4 & 71 & 81 & 91 & 67 & 100 & 5 & $\mathbf{0}$ & $\mathbf{0}$ & $\mathbf{0}$ & $\mathbf{0}$ \\
\hline 5 & 76 & 88 & 100 & 100 & 100 & 5 & 0 & $\mathbf{0}$ & $\mathbf{0}$ & $\mathbf{0}$ \\
\hline 6 & 81 & 88 & 100 & 100 & 100 & 5 & $\mathbf{0}$ & $\mathbf{0}$ & $\mathbf{0}$ & 0 \\
\hline 7 & 86 & 88 & 100 & 100 & 100 & 5 & $\mathbf{0}$ & $\mathbf{0}$ & $\mathbf{0}$ & $\mathbf{0}$ \\
\hline 8 & 86 & 88 & 100 & 100 & 100 & $\mathbf{0}$ & $\mathbf{0}$ & $\mathbf{0}$ & $\mathbf{0}$ & $\mathbf{0}$ \\
\hline 9 & 86 & 88 & 100 & 100 & 100 & 5 & $\mathbf{0}$ & $\mathbf{0}$ & $\mathbf{0}$ & $\mathbf{0}$ \\
\hline 10 MVP & 81 & 88 & 100 & 100 & 100 & 0 & 0 & 0 & 0 & $\mathbf{0}$ \\
\hline
\end{tabular}

However, there is a marked difference between the two tables when we consider the percentage of the time when real estate reached its 20 percent upper bound. Table 2 shows that real estate hardly ever reached its maximum allocation when it is tested for return enhancement ability, except for a few case for the 5-year investment horizon. In contrast, Table 3 shows that real estate often achieved its reached its upper bound when it is added to the mixed-asset portfolio in order to risk portfolio risk. This is especially true for the lower risk portfolios and for the longer holding periods. As a consequence, an allocation of 20 percent to real estate in the mixed-asset portfolio, as suggested in the literature, can only be justified if the investor considers purchasing property for its diversification benefits and is prepared to hold the asset for about 25year!

Table 3: Percentage of the Time When Real Estate Achieved a Positive Allocation and Reached its Upper Bound (Reducing Risk)

\begin{tabular}{l|ccccc|ccccc}
\hline & \multicolumn{4}{|c|}{$\begin{array}{c}\text { Percentage of the Time When Real } \\
\text { Estate Achieved a Positive Allocation }\end{array}$} & \multicolumn{4}{c}{$\begin{array}{c}\text { Percentage of the Time when Real } \\
\text { Estate Reached its Upper Bound }\end{array}$} \\
\hline & 5 & 10 & 15 & 20 & 25 & 5 & 10 & 15 & 20 & 25 \\
\hline 1 MRP & 24 & 13 & 9 & 0 & 0 & 14 & 0 & 9 & 0 & 0 \\
2 & 48 & 63 & 55 & 67 & 100 & 19 & 0 & 9 & 0 & 0 \\
3 & 52 & 75 & 73 & 67 & 100 & 14 & 0 & 9 & 0 & 0 \\
4 & 67 & 81 & 91 & 67 & 100 & 10 & 0 & 9 & 0 & 0 \\
5 & 71 & 88 & 100 & 100 & 100 & 10 & 0 & 9 & 0 & 0 \\
6 & 76 & 88 & 100 & 100 & 100 & 10 & 6 & 9 & 0 & 0 \\
7 & 81 & 88 & 100 & 100 & 100 & 5 & 19 & 9 & 0 & 100 \\
8 & 86 & 88 & 100 & 100 & 100 & 10 & 31 & 0 & 17 & 100 \\
9 & 81 & 88 & 100 & 100 & 100 & 10 & 31 & 27 & 17 & 100 \\
10 MVP & $\mathbf{8 1}$ & $\mathbf{8 8}$ & 100 & 100 & 100 & 10 & 25 & 27 & 17 & 100 \\
\hline
\end{tabular}

What Assets Does Real Estate Replace?

Tables 4 and 5 present the percentage of the time real estate replaces the alternative asset classes and the average proportions coming from each asset for the two tests (return enhancement and risk reduction) and for the five investment horizons.

Table 4 shows that when real estate has a positive allocation in the mixed-asset portfolio designed to enhance returns it tends to replace bonds, especially for the lower risk portfolios and the longer the holding period. This is not unexpected as real estate generally offers higher returns than bonds, especially in the long-run. In contrast, although real estate sometimes replaces equity it for much less of the time 
and generally in the higher portfolio return levels and for the shortest holding periods. When real estate replaces cash it is at the higher portfolio return levels for the shorter investment horizons but at the lower risk levels for the longer holding periods.

Table 4: Percentage of Time Real Estate Replaces: Equity, Bonds and Cash and the Average Proportions from each Asset Class (Enhancing Returns)

\begin{tabular}{|c|c|c|c|c|c|c|c|c|c|c|c|c|c|c|c|}
\hline \multirow{2}{*}{$\frac{\% \text { of }}{\text { Time }}$} & \multicolumn{3}{|c|}{ 5-year } & \multicolumn{3}{|c|}{ 10-year } & \multicolumn{3}{|c|}{ 15-year } & \multicolumn{3}{|c|}{ 20-year } & \multicolumn{3}{|c|}{ 25-year } \\
\hline & $\mathbf{E}$ & B & C & $\mathbf{E}$ & B & C & $\mathbf{E}$ & B & C & $\mathbf{E}$ & B & C & $\mathbf{E}$ & B & C \\
\hline MRP & 19 & 57 & 10 & 6 & 75 & 0 & 36 & 27 & 0 & 67 & 33 & 0 & 0 & 100 & 0 \\
\hline 2 & 14 & 38 & 67 & 31 & 50 & 56 & 27 & 64 & 36 & 33 & 67 & 67 & 0 & 100 & 0 \\
\hline 3 & 19 & 43 & 57 & 31 & 63 & 56 & 27 & 73 & 45 & 33 & 67 & 67 & 0 & 100 & 0 \\
\hline 4 & 29 & 52 & 62 & 19 & 63 & 56 & 18 & 82 & 45 & 33 & 67 & 67 & 0 & 100 & 0 \\
\hline 5 & 33 & 57 & 62 & 38 & 63 & 50 & 18 & 82 & 64 & 17 & 83 & 100 & 0 & 100 & 0 \\
\hline 6 & 29 & 67 & 62 & 38 & 63 & 50 & 18 & 82 & 64 & 17 & 83 & 100 & 0 & 100 & 100 \\
\hline 7 & 29 & 71 & 62 & 38 & 63 & 50 & 18 & 82 & 64 & 17 & 83 & 100 & 0 & 100 & 100 \\
\hline 8 & 29 & 71 & 62 & 31 & 69 & 44 & 18 & 82 & 64 & 17 & 83 & 100 & 0 & 100 & 100 \\
\hline 9 & 24 & 76 & 57 & 38 & 63 & 50 & 18 & 82 & 64 & 17 & 83 & 100 & 0 & 100 & 100 \\
\hline MVP & 24 & 71 & 57 & 38 & 63 & 63 & 18 & 82 & 64 & 17 & 83 & 100 & $\mathbf{0}$ & 100 & 100 \\
\hline$\%$ & \multicolumn{3}{|c|}{ 5-year } & \multicolumn{3}{|c|}{ 10-year } & \multicolumn{3}{|c|}{ 15-year } & \multicolumn{3}{|c|}{ 20-year } & \multicolumn{3}{|c|}{ 25-year } \\
\hline From & $\mathbf{E}$ & B & C & $\mathbf{E}$ & B & C & $\mathbf{E}$ & B & C & $\mathbf{E}$ & B & C & $\mathbf{E}$ & B & C \\
\hline MRP & 20 & 71 & 8 & 8 & 92 & $\mathbf{0}$ & 57 & 43 & 0 & 67 & 33 & 0 & $\mathbf{0}$ & 100 & $\mathbf{0}$ \\
\hline 2 & 4 & 28 & 68 & 23 & 27 & 50 & 19 & 48 & 33 & 33 & 5 & 61 & $\mathbf{0}$ & 100 & $\mathbf{0}$ \\
\hline 3 & 10 & 40 & 50 & 23 & 41 & 36 & 19 & 55 & 26 & 33 & 13 & 53 & 0 & 100 & $\mathbf{0}$ \\
\hline 4 & 10 & 44 & 45 & 4 & 55 & 41 & 10 & 71 & 19 & 33 & 32 & 35 & $\mathbf{0}$ & 100 & $\mathbf{0}$ \\
\hline 5 & 14 & 48 & 38 & 18 & 53 & 29 & 2 & 73 & 26 & 1 & 57 & 42 & $\mathbf{0}$ & 100 & $\mathbf{0}$ \\
\hline 6 & 8 & 57 & 35 & 18 & 55 & 27 & 2 & 70 & 28 & 1 & 55 & 44 & 0 & 96 & 4 \\
\hline 7 & 8 & 61 & 32 & 18 & 56 & 27 & 2 & 68 & 30 & 1 & 55 & 44 & 0 & 91 & 9 \\
\hline 8 & 7 & 62 & 30 & 16 & 63 & 21 & 2 & 67 & 31 & 1 & 56 & 43 & 0 & 87 & 13 \\
\hline 9 & 4 & 69 & 27 & 18 & 57 & 25 & 2 & 68 & 29 & 1 & 57 & 42 & 0 & 83 & 17 \\
\hline MVP & 4 & 68 & 28 & 6 & 57 & 37 & 2 & 71 & 27 & 1 & 58 & 41 & 0 & 80 & 20 \\
\hline
\end{tabular}

Table 5: Percentage of Time Real Estate Replaces: Equity, Bonds and Cash and the Average Proportions from each Asset Class (Reducing Risk)

\begin{tabular}{|c|c|c|c|c|c|c|c|c|c|c|c|c|c|c|c|}
\hline$\%$ of & \multicolumn{3}{|c|}{ 5-year } & \multicolumn{3}{|c|}{ 10-year } & \multicolumn{3}{|c|}{ 15-year } & \multicolumn{3}{|c|}{ 20-year } & \multicolumn{3}{|c|}{ 25-year } \\
\hline Time & $\mathbf{E}$ & B & C & $\mathbf{E}$ & B & C & $\mathbf{E}$ & B & C & $\mathbf{E}$ & B & C & $\mathbf{E}$ & B & C \\
\hline MRP & 29 & 29 & 5 & 19 & 38 & 0 & 9 & 36 & 0 & 0 & 33 & 0 & 0 & 100 & 0 \\
\hline 2 & 38 & 57 & 33 & 38 & 69 & 56 & 9 & 82 & 45 & 17 & 100 & 67 & 0 & 100 & 0 \\
\hline 3 & 38 & 57 & 33 & 44 & 75 & 38 & 27 & 73 & 45 & 33 & 83 & 67 & 0 & 100 & 0 \\
\hline 4 & 43 & 57 & 43 & 38 & 75 & 44 & 9 & 100 & 36 & 33 & 83 & 67 & 0 & 100 & 0 \\
\hline 5 & 43 & 62 & 38 & 44 & 75 & 50 & 18 & 91 & 55 & 33 & 83 & 100 & 0 & 100 & 0 \\
\hline 6 & 48 & 67 & 33 & 44 & 75 & 50 & 18 & 91 & 64 & 33 & 83 & 100 & 0 & 100 & 100 \\
\hline 7 & 48 & 71 & 33 & 44 & 75 & 50 & 18 & 91 & 64 & 33 & 83 & 100 & 0 & 100 & 100 \\
\hline 8 & 48 & 76 & 29 & 38 & 75 & 44 & 27 & 91 & 55 & 33 & 83 & 100 & 100 & 100 & 100 \\
\hline 9 & 48 & 76 & 29 & 44 & 75 & 38 & 18 & 91 & 55 & 33 & 83 & 100 & 100 & 100 & 100 \\
\hline MVP & 48 & 76 & 33 & 25 & 75 & 44 & 18 & 91 & 55 & 33 & 83 & 100 & 100 & 100 & 100 \\
\hline$\%$ & \multicolumn{3}{|c|}{ 5-year } & \multicolumn{3}{|c|}{ 10-year } & \multicolumn{3}{|c|}{ 15-year } & \multicolumn{3}{|c|}{ 20-year } & \multicolumn{3}{|c|}{ 25-year } \\
\hline From & $\mathbf{E}$ & B & C & $\mathbf{E}$ & B & C & $\mathbf{E}$ & B & C & $\mathbf{E}$ & B & C & $\mathbf{E}$ & B & C \\
\hline MRP & 49 & 51 & 0 & 21 & 79 & $\mathbf{0}$ & 12 & 88 & 0 & 0 & 100 & $\mathbf{0}$ & $\mathbf{0}$ & 100 & 0 \\
\hline 2 & 31 & 47 & 22 & 19 & 49 & 32 & 4 & 58 & 38 & 0 & 59 & 41 & $\mathbf{0}$ & 100 & 0 \\
\hline 3 & 31 & 48 & 20 & 25 & 60 & 14 & 22 & 56 & 22 & 18 & 42 & 40 & 0 & 100 & 0 \\
\hline 4 & 34 & 45 & 21 & 10 & 66 & 23 & 4 & 88 & 8 & 17 & 55 & 28 & 0 & 100 & 0 \\
\hline 5 & 34 & 54 & 13 & 10 & 64 & 26 & 8 & 79 & 13 & 3 & 58 & 39 & 0 & 100 & 0 \\
\hline 6 & 32 & 58 & 11 & 9 & 66 & 25 & 8 & 76 & 16 & 5 & 54 & 41 & $\mathbf{0}$ & 96 & 4 \\
\hline 7 & 29 & 62 & 9 & 9 & 67 & 24 & 8 & 74 & 18 & 6 & 54 & 40 & 0 & 91 & 9 \\
\hline 8 & 22 & 69 & 10 & 6 & 73 & 21 & 8 & 73 & 19 & 7 & 55 & 38 & 3 & 82 & 15 \\
\hline 9 & 25 & 67 & 8 & 13 & 72 & 14 & 7 & 75 & 18 & 7 & 57 & 36 & 10 & 70 & 20 \\
\hline MVP & 27 & 64 & 9 & 5 & 75 & 20 & 7 & 78 & 16 & 7 & 60 & 33 & 17 & 58 & 25 \\
\hline
\end{tabular}

A similar picture emerges when real estate is employed to reduce portfolio risk. Real estate tends to replace bonds for the majority of the time, closely followed by cash and then equities. However, as Table 5 shows in this case real estate tends to replace the equities and bonds more often than above and cash less than before. Again this is to be expected as cash offers low individual and portfolio risk to the mixed-asset 
portfolio, particularly at the low return levels and so cannot be replaced by real estate. In contrast, equities and bonds both display higher levels of risk than real estate and so will be replaced more often. These results suggests that the position of real estate in the mixed-asset portfolio changes across the efficient frontier from a return enhancer in the high return portfolios to a risk reducer for the lower return portfolios consequently the assets it replaces also changes, especially for longer investment horizons.

\section{The Marginal Impact on Risk and Return}

An issue not yet addressed is the amount of increase in portfolio returns or reduction in portfolio risk that can be expected from the addition of real estate real estate. To consider real estate for portfolio inclusion, an institutional investor must be satisfied that the incremental reward or diversification opportunity from adding this asset class is worth the effort and expense involved in researching the asset, hiring and paying a manager, and monitoring the manager's performance.

Table 6 shows the average allocation to real estate and marginal return differentials (measured in basis points); at each portfolio return level and for the five investment horizons. Differences in return were calculated at points of identical risk (standard deviation) for the portfolios with real estate compared with efficient portfolios without real estate.

The impact of adding real estate was most pronounced for the MVP portfolios, where real estate showed the largest allocations and greatest marginal return impact; over all investment holding periods. The allocations and marginal increases declined at the higher return level portfolios and were smallest at the MRP. However, the gains in return are small at around 30 basis points per annum, with gains of less than 5 basis points in most situations, except for the 5-year holding periods when the gains are considerably higher at all portfolio levels. Whether these small increases in return are sufficient to justify an allocation to real estate in the mixed-asset portfolio is debatable.

Table 6: Summary Annualised Aggregate Return Enhancement Results

\begin{tabular}{l|ccccc|ccccc}
\hline & \multicolumn{5}{|c|}{ Real Estate Allocation } & \multicolumn{4}{c}{ Average Return Enhancement Bp } \\
\hline & 5 & 10 & 15 & 20 & 25 & 5 & 10 & 15 & 20 & 25 \\
\hline 1 MRP & 1.2 & 0.0 & 0.0 & 0.0 & 0.0 & 6 & 0 & 0 & 0 & 0 \\
2 & 3.1 & 2.4 & 1.9 & 1.9 & 2.8 & 16 & 5 & 2 & 2 & 5 \\
3 & 3.9 & 3.3 & 3.5 & 3.6 & 5.6 & 26 & 11 & 5 & 5 & 10 \\
4 & 4.4 & 3.9 & 4.6 & 5.1 & 8.5 & 33 & 17 & 9 & 8 & 15 \\
5 & 4.9 & 4.8 & 5.8 & 6.5 & 10.5 & 43 & 24 & 12 & 12 & 19 \\
6 & 5.3 & 5.5 & 6.8 & 7.7 & 11.5 & 53 & 30 & 16 & 16 & 23 \\
7 & 5.8 & 6.2 & 7.7 & 8.7 & 12.5 & 65 & 36 & 20 & 19 & 26 \\
8 & 5.9 & 7.2 & 8.5 & 10.4 & 13.6 & 76 & 43 & 23 & 23 & 30 \\
9 & 6.8 & 7.7 & 9.3 & 10.6 & 14.6 & 89 & 51 & 27 & 27 & 33 \\
10 MVP & 6.3 & 8.4 & 10.1 & 11.5 & 15.6 & 103 & 61 & 32 & 31 & 37 \\
\hline
\end{tabular}

In contrast, to the small increases in return offered by including real estate in the mixed-asset portfolio the reductions in risk shown in Table 7 are substantial. Table 7 shows the average allocation to real estate and the mean marginal reduction in risk (measured in basis points); at each portfolio return level and for the five investment 
horizons. Differences in risk were calculated at points of identical return for portfolios with and without real estate.

Table 7 shows that the average allocation to real estate in its risk reducing capacity is greater than that for its return enhancement at all portfolio risk levels and over all investment horizons. Indeed, in the case of the 25-year data real estate reached its upper bound of 20 percent. Table 7 also shows that like the figures in Table 6 the impact on portfolio risk of adding real estate was more pronounced for the MVP portfolios, with the allocations falling at the higher return level portfolios and was smallest at the MRP, except for the 5-year investment horizon where the opposite is the case.

Table 7: Summary Annualised Aggregate Risk Reduction Results

\begin{tabular}{l|ccccc|ccccc}
\hline & \multicolumn{5}{|c|}{ Real Estate Allocation } & \multicolumn{4}{c}{ Average Risk reduction Bp } \\
\hline & 5 & 10 & 15 & 20 & 25 & 5 & 10 & 15 & 20 & 25 \\
\hline 1 MRP & 4.2 & 1.8 & 1.8 & 0.0 & 0.0 & -118 & -25 & -23 & 0 & 0 \\
2 & 6.4 & 5.9 & 4.6 & 3.4 & 10.6 & -116 & -43 & -30 & -14 & -68 \\
3 & 6.4 & 6.7 & 6.3 & 5.3 & 12.7 & -117 & -53 & -35 & -17 & -85 \\
4 & 6.9 & 7.7 & 7.7 & 7.1 & 14.7 & -120 & -61 & -41 & -23 & -103 \\
5 & 7.4 & 8.9 & 8.9 & 8.3 & 16.8 & -117 & -70 & -46 & -28 & -124 \\
6 & 7.7 & 10.1 & 10.1 & 9.8 & 18.9 & -113 & -81 & -52 & -35 & -148 \\
7 & 8.3 & 11.1 & 11.2 & 11.2 & 20.0 & -111 & -92 & -58 & -43 & -166 \\
8 & 9.3 & 12.9 & 11.4 & 12.5 & 20.0 & -104 & -99 & -64 & -51 & -175 \\
9 & 9.1 & 12.5 & 13.5 & 13.6 & 20.0 & -97 & -107 & -71 & -59 & -183 \\
10 MVP & 8.9 & 12.8 & 14.4 & 14.5 & 20.0 & -91 & -109 & -79 & -67 & -189 \\
\hline
\end{tabular}

Finally, the reductions in portfolio risk are generally greater than the gains in return. For example, for the 15-year investment horizon the reduction in portfolio risk at the lower end of the efficient frontier (portfolios 7-9) is between 58 and 79 basis points and is three times that compared with its return enhancement for the same portfolios (20-27 basis points). For the 25-year holding period this ratio is even greater, where the reduction in risk is more than seven times that as for the gain in return. This implies that direct real estate should be considered as diversify rather than a return enhancer in the mixed-asset portfolio. However, the reverse is the case for the 5-year holding period where the gain in return is on average greater than the reduction in risk for the $\mathrm{MVP}^{4}$.

\section{Conclusions}

This study has examined the attractiveness of direct real estate in the context of a mixed-asset portfolio compared with portfolios, without real estate, firstly holding the risk constant and secondly the portfolio return constant. The results highlight a number of issues in relation to the role of direct real estate within a mixed-asset framework. First, the results suggest strongly that real estate has possessed the attribute of consistency in optimised portfolios. Real estate constantly had positive allocations over time periods ranging from 5- to 25-years, and for most levels of portfolio return, irrespective of whether real estate is used to enhance returns or reduce risk. Secondly, the benefits from including real estate in the mixed-asset portfolio tend to increase as the investment horizon is extended. This implies that direct real estate should be considered as a strategic asset in the mixed-asset portfolio

\footnotetext{
${ }^{4}$ However, the results for the 5-year investment horizons are dominated by a few extreme outliers.
} 
especially for those investors with longer holding periods. Third, the position of real estate changes across the efficient frontier from its return enhancing ability to its risk reducing facility. As a consequence the asset that needs to be replaced depends on whether an investor wishes to increase returns or lower risk or both. Finally, the results show that the gain in return from adding real estate to the mixed-asset portfolio is typically less compared with the reduction in portfolio risk. This would indicate that as an investor moves along the frontier the rationale behind the inclusion of real estate alters, with increasing emphasis being placed on the assets risk reduction qualities rather than its return enhancing capabilities. In other words, direct real estate should be considered as diversify rather than a return enhancer in the mixedasset portfolio. 


\section{References}

Chopra, V.K. (1993) Mean-Variance Revisited: Near Optimal Portfolios and Sensitivity to Input Variations, Journal of Investing.

Chopra, V.K., Hensel, C.R. and Turner, A.L. (1993) Massaging Mean Variance Inputs: Returns form Alternative Global Investment Strategies in the 1980's, Management Science, 39, 845-855.

Collett, D, Lizieri C. and Ward C.W.R. (2003) Timing and the Holding Periods of Institutional Real Estate, Real Estate Economics, 31, 2, 205-222

Fisher, J.D., Geltner, D.M. and Webb, R.B. (1994) Value Indices of Commercial Real Estate: A Comparison of Index Construction Methods, Journal of Real Estate Finance and Economics, 9, 137-164

Fisher, J.D. and Young, M.S. (2000) Institutional Property Tenure: Evidence from the NCRIEF Database, Journal of Real Estate Portfolio Management, 6, 4, 327-338

Folger, H.R. (1984) 20\% in Real Estate: Can Theory Justify It? The Journal of Portfolio Management, Winter, 6-13

Geltner, D.M. (1993) Estimating Market Values from Appraised Values without Assuming an Efficient Market, Journal of Real Estate Research, 8, 325-345

Corgel, J.B. and deRoos, J.A. (1999) Recovery of Real Estate Returns for Portfolio Allocation, Journal of Real Estate Finance and Economics, 18, 279-296

Frost, P.A. and Savarino, J.E. (1988) For Better Performance: Constrain Portfolio Weights, Journal of Portfolio Management, Fall, 29-34.

Jorion, P. (1985) International Portfolio Diversification with Estimation Risk, Journal of Business, 259-78

Jorion, P. (1992) Portfolio Optimisation in Practice, Financial Analysts Journal, January-February, 68-74

Markowitz, H. M. (1952) Portfolio Selection, Journal of Finance, 7, 1, 77-91

Michaud, R. O. (1989) The Markowitz Optimisation Enigma: is 'Optimized' Optimal? Financial Analysts Journal, January/February, 31-42

Michaud, R. O. (1998) Efficient Asset Management, Harvard Business School Press, Boston Massachusetts, USA

Seiler, M.J., Webb, J.R. and Myer, F.C.N. (1999) Diversification Issues in Real estate Investment, Journal of Real Estate Literature, 7, 2, 163-179 
Sivitanides, P.S. (1997) Why Invest in Real Estate: An Asset Allocation Perspective, Real Estate Issues, 22, April, 30-37

Stevenson, S. (2000) Constraining Optimal Portfolios and The Effect on Real Estates Allocation, Journal of Property Investment \& Finance, 18, 4, 488-506

Sweeney, F. (1988) 20\% in Property - a Viable Strategy? Estates Gazette, 13 February, 26-28 